\title{
Evidence-based guidelines for hypofractionated radiation in breast cancer: conclusions of the Catalan expert working group
}

\author{
Arantxa Eraso ${ }^{1} \cdot$ Javier Sanz ${ }^{2}(1) \cdot$ Meritxell Mollà $^{3} \cdot$ Vicky Reyes $^{4} \cdot$ Agustí Pedro $^{5} \cdot$ Meritxell Arenas $^{6}$. \\ Evelyn Martinez $z^{7}$ Rosa Ballester ${ }^{8} \cdot$ Maria José Cambra $^{9} \cdot$ Virginia García $^{10}$. Joan Lluis Prades ${ }^{11}$. Josep M. Borras ${ }^{11}$. \\ Manuel Algara ${ }^{2}$
}

Received: 17 November 2021 / Accepted: 28 January 2022 / Published online: 21 February 2022

(c) The Author(s) 2022

\begin{abstract}
Introduction Daily, moderate hypofractionation has become standard treatment for breast cancer following breast-conserving surgery, although substantial variation exists in its use. This paper describes the generation of consensus-based recommendations for the utilisation of this therapy at the healthcare system level and compares these to American Society for Radiation Oncology (ASTRO) guidelines.

Materials and methods Consensus-based guidelines were developed in three steps, including a systematic literature review and involvement of radiation oncologists specialising in breast cancer in Catalonia: (a) creation of a working group and evidence review; (b) consideration of the levels of evidence and agreement on the formulation of survey questions; and (c) performance of survey and development of consensus-based recommendations. Results were compared to the ASTRO recommendations.

Results Consensus was above $80 \%$ for 10 of the 14 survey items. Experts supported hypofractionated radiotherapy for all breast cancer patients aged 40 years or more; with invasive carcinoma and breast-conserving surgery; without radiation of lymph nodes; and regardless of the tumour size, histological grade, molecular subtype, breast size, laterality, other treatment characteristics, or need for a boost. Over half favoured its use in all situations, even where available scientific evidence is insufficient. The resulting recommendations and the quality of the evidence are comparable to those from ASTRO, despite some differences in the degree of consensus.

Conclusion Specialists agree that hypofractionation is the standard treatment for breast cancer following breast-conserving surgery, but some specific areas require a higher level of evidence before unequivocally extending indications.
\end{abstract}

Keywords Breast cancer $\cdot$ Radiotherapy $\cdot$ Hypofractionation

\section{Introduction}

Following breast-conserving surgery for breast cancer, daily, moderate hypofractionation has become standard treatment $[1,2]$. Results from randomised trials do not support the use of classic fractionation of $2 \mathrm{~Gy}$ in most patients [3, 4], and studies have confirmed the effectiveness of hypofractionated regimens with similar tolerance [5]. Indications for its use have also broadened with the growing body of evidence showing its utility under other circumstances, for example with irradiation of lymph nodes [6] or the chest

Javier Sanz

jsanz@psmar.cat

Extended author information available on the last page of the article wall following mastectomy [7], or in patients of all ages [8]. However, there are substantial variations in the use of hypofractionation across different centres and countries [9, 10]. In a previous study, our group assessed its use for breast cancer in Catalonia, Spain [11], finding that it ranged from 8.9 to $74.7 \%$ of patients treated with a curative intent. In addition, specific indications for the treatment varied, both between services and among the different professionals that staff fed them.

In light of this heterogeneity and taking as a reference the American Society for Radiation Oncology (ASTRO) consensus guidelines on hypofractionation for breast cancer [12], we decided to launch a consensus-building process to establish recommendations for this breast cancer treatment in our region. Greater knowledge of the real indications and 
agreement among professionals should lead to an expansion of its use as a standard indication in Catalonia, promote equitable access, reduce differences between public healthcare services, and improve patients' quality of life by avoiding the need for unnecessary travel and its associated inconveniences. This study describes the methods used to reach a consensus as well as the resulting recommendations as they compare to the ASTRO guidelines [12].

\section{Materials and methods}

\section{Process}

In 2018, the Catalonian Cancer Plan approved the process to develop consensus-based guidelines on the use of hypofractionation for breast cancer. Work began in February 2018 and ended in May 2019, and consisted of three phases: (a) creation of a working group and systematic review of the evidence; (b) consideration of the levels of evidence and consensus on the formulation of survey questions; and (c) performance of the survey and development of consensus-based recommendations. Main invited experts were radiation oncologists specialising in breast cancer and working in the 10 public treatment centres in Catalonia; experts in evidence-based medicine, project management and biostatistics; collaborators with experience in searching and managing bibliographic databases; and managers and administrators involved in breast cancer treatment (heads of services, plus the Director of the Catalonian Cancer Plan) (Fig. 1). Altogether, a total of 26 professionals were invited to join the working group, and all accepted.

A steering committee of four members was created, bringing together professionals with responsibilities in clinical and technical leadership as well as project management and monitoring. Its functions were to define the objectives of the guidelines and the criteria for the bibliographic review; formulate the final clinical questions; synthesise and evaluate the evidence; and draft the final document.

In May 2018, the first in-person meeting of the consensus-building process took place. Fourteen questions were selected to answer the main controversial issues. The 14 survey questions were approved, and the most current literature was reviewed. The questions were then subjected to an independent vote among all experts of the working group. The vote was conducted online to avoid any influence from

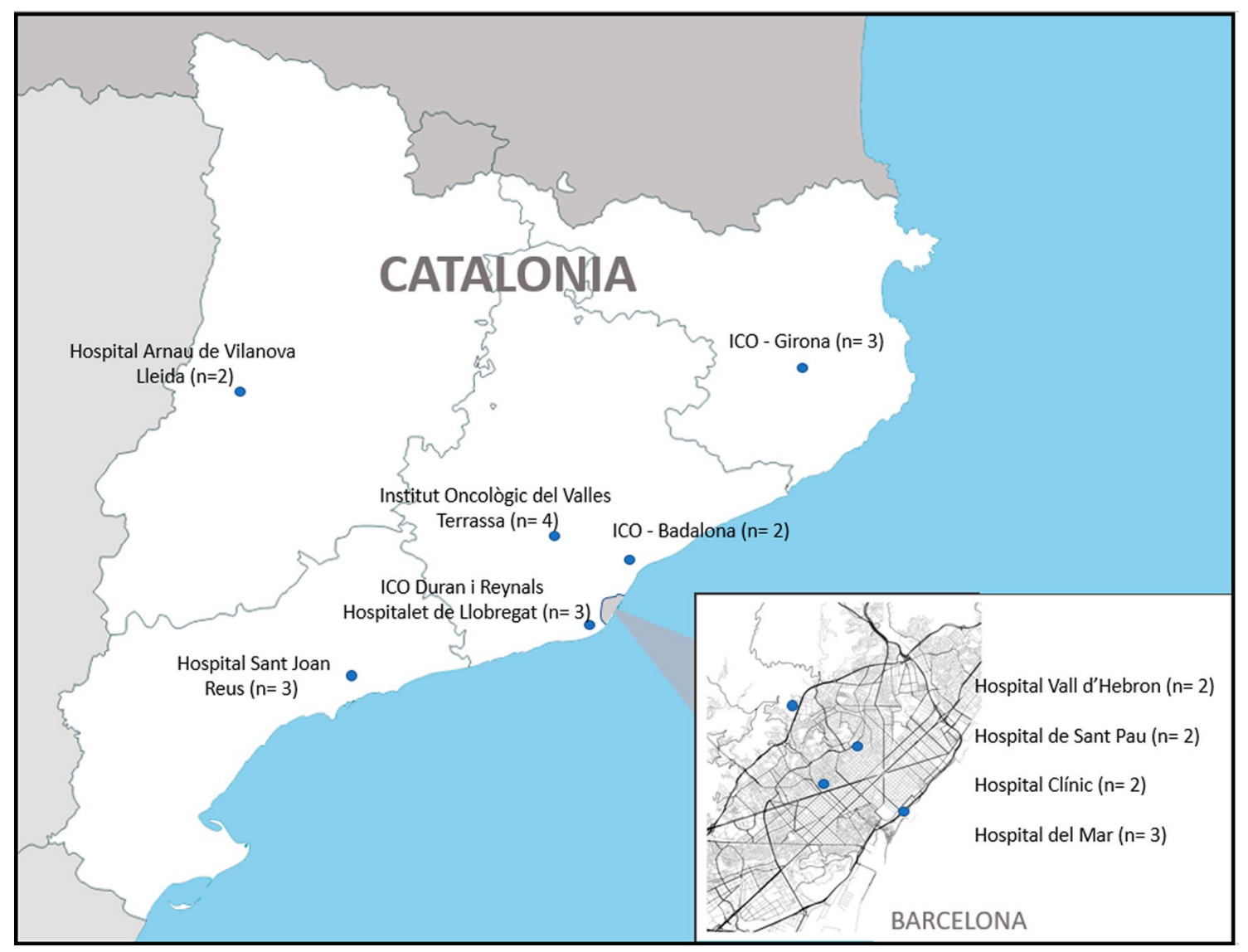

Fig. 1 Participating centres and number of surveyed experts 
other experts of the group and enable a response after collating all the information.

In January 2019, the draft recommendations were presented to the working group during a second physical meeting to reach a final consensus among all the experts. The information gathered and the collective responses from the group were presented for each question, one by one, and the discrepancies and justifications were considered in turn. The recommendations were then drafted by consensus, and the direction and strength of each were finalised by May 2019 . The methodological process is shown in Fig. 2.

\section{Literature review}

The consensus-based guidelines were informed by an initial systematic literature review of records published in English between 1 January 2004 and 30 January 2019 and indexed in MEDLINE (PubMed). The primary search terms used were "hypofractionated", "radiotherapy" and "breast neoplasm".

The selection criteria for inclusion were randomised controlled trials (RCTs), meta-analyses of RCTs, and prospective observational studies that involved more than 100 participants. The intervention under assessment was hypofractionated external beam radiotherapy for early or locally advanced breast cancer, regardless of lymph node irradiation or additional boost. The outcomes of interest were control of breast cancer (disease-free survival, cancer-specific survival, and overall survival) and acute and late toxicity. The bibliographic search yielded 141 records. After screening the abstracts, 31 full-text records were evaluated, all of which fulfilled the established selection criteria (Fig. 3).

\section{Level of evidence, recommendations, and consensus-building methodology}

The GRADE system was applied to classify the quality of the body of evidence and the strength of the recommendations $[13,14]$, in line with the approach used by ASTRO

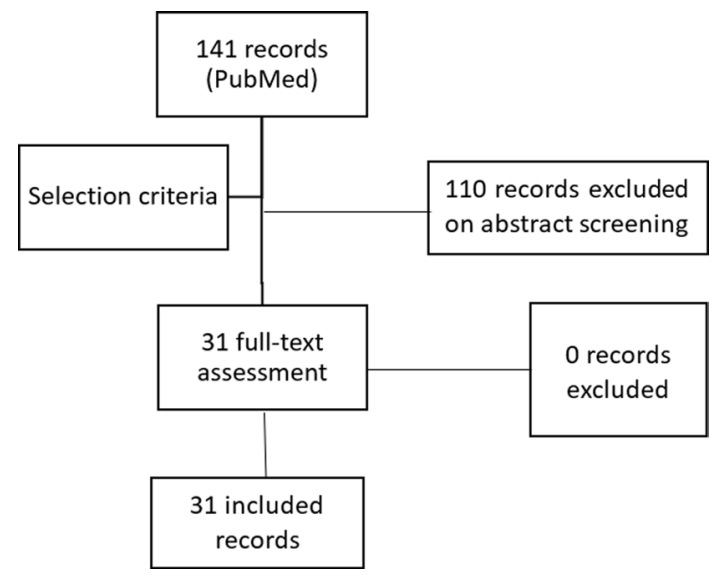

Fig. 3 Results of the bibliographic search

and the American Society for Clinical Oncology (ASCO) for their recommendations on hypofractionation in breast and prostate cancer $[12,15]$.

The recommendations were classified as strong or conditional, according not only to the quality of evidence, but also to other factors like the risk-benefit trade-off, the values and preference of patients and professionals, and the costs and resources involved. The members of the working group completed the survey by marking their agreement in the items on a scale of 0 to 10 , with higher scores indicating stronger agreement.

A strong recommendation indicates that the working group concluded that the benefits of the intervention clearly outweighed the harms (or vice versa), and that 'all or almost all of informed professionals would follow the recommendation. Conditional recommendations were made when the risks and benefits were similar or uncertain. According to our assessment scale, scores of 8 or above were considered a strong endorsement.

The quality of evidence for each recommendation was initially deemed high or low using ASTRO's criteria
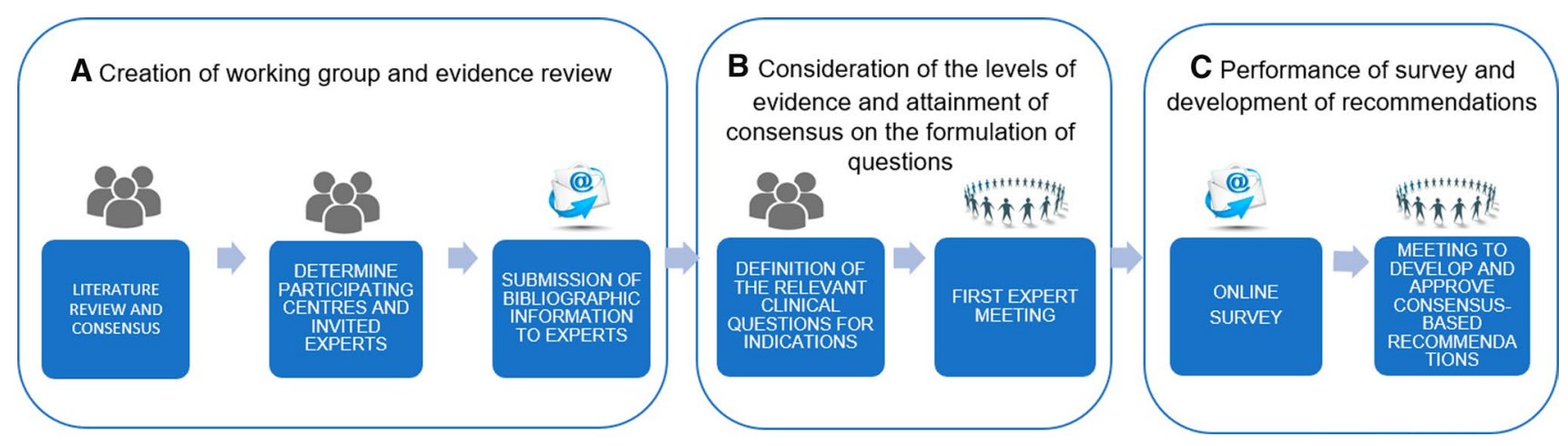

Fig. 2 Methodology for the consensus-building process 
[12] and Balsheim's grades of evidence [14], according to whether the evidence was generated in experimental or observational studies. Other considerations were then taken into account to finalise the level of evidence as high, moderate, or low (Table 1).

- High: We are confident that the true effect is similar to the estimated effect.

- Moderate: We believe that the true effect is probably close to the estimated effect but substantially difference also is possible.

- Low: We have limited confidence in the estimated effect: the true effect might be markedly different from the estimated effect.

In addition, experts' opinions were integrated in the process using ASCO's modified Delphi approach [16], producing a percentage of consensus among the working group. Members took an online survey, registering their level of agreement on a scale of 0 to 10 . The pre-defined cutoff for consensus was $80 \%$.

Results were compared to the ASTRO recommendations also considering quality of evidence and the consensus reached.

\section{Results}

All the invited centres participated in every meeting held, all controversial issues were discussed and finally answered to the corresponding questionnaires submitted.

With regard to the 14 questions considered, these are detailed in Table 2, along with the level of evidence, degree of consensus, and strength of the recommendation.
Our results are comparable to the ASTRO guidelines [12] in terms of the final recommendations and the quality of evidence supporting them. However, there were some differences in the level of consensus achieved, for example in patients under the age of 40 years: compared to ASTRO consensus, the agreement on the use of hypofractionation in these cases was $93 \%$, compared to $63 \%$ in our analysis. These differences are probably due to our classification of patient age into three brackets: less than 40 years, 40 to 50 years, and more than 50 years.

Unlike the ASTRO guidelines, we included questions about hypofractionation in patients receiving a mastectomy or who required irradiation of the lymph node chain. For these indications, the degree of consensus was low at $64 \%$ and $59 \%$, respectively, in consonance with the low quality of evidence.

\section{Discussion}

Despite the growing evidence of the association between hypofractionated treatment and improved clinical and care quality for patients with breast cancer, the direct translation to clinical practice has been limited. The possible reasons for this lag are numerous and range from missed opportunities following positive results from clinical trials, to knowledge gaps and uncertainty, controversies, irrelevant or conflicting evidence, and vested or conflicting interests [28]. The considerable volume of scientific publications makes it difficult to attain deep knowledge based on the analysis of available evidence; rather, this is often synthesised at an individual level.

Uptake of hypofractionation has been slow for breast cancer in public hospitals in Catalonia, with considerable variability in clinical practice, as reported by Prades et al. [11]. This delay in the translation of evidence to practice

Table 1 American Society for Clinical Oncology (ASCO) criteria for assessing the quality of evidence

\begin{tabular}{|c|c|c|}
\hline Rating & Quality criteria & Definition \\
\hline High & $\begin{array}{l}\text { - } \geq 2 \text { well-conducted RCTs with generalisable results or meta- } \\
\text { analysis of these trials }\end{array}$ & $\begin{array}{l}\text { It is very likely that the true effect is close to the estimated effect, } \\
\text { based on the body of evidence }\end{array}$ \\
\hline Moderate & $\begin{array}{l}\text { - } 1 \text { well-conducted, generalisable RCT or meta-analysis of trials; } \\
\text { or } \\
\text { - } \geq 2 \text { RCTs with some limitations or lack of generalisability; or } \\
\text { - } \geq 2 \text { well-conducted observational studies with consistent } \\
\text { results }\end{array}$ & $\begin{array}{l}\text { It is likely that the true effect is close to the estimated effect, based } \\
\text { on the body of evidence, but it is possible that it is substantially } \\
\text { different }\end{array}$ \\
\hline Low & $\begin{array}{l}\text { - } 1 \text { RCT with some limitations or lack of generalisability; or } \\
-\geq 1 \text { RCTs with serious shortcomings, lack of generalisability, } \\
\text { or extremely small sample sizes; or } \\
\text { - } \geq 2 \text { observational studies with inconsistent findings, small } \\
\text { sample sizes, or other problems that may cloud the interpreta- } \\
\text { tion of data }\end{array}$ & $\begin{array}{l}\text { The true effect may be substantially different from the estimated } \\
\text { effect. There is a risk that future research may significantly alter } \\
\text { the estimated size of effect or the interpretation of the results }\end{array}$ \\
\hline
\end{tabular}

$R C T$ randomised controlled trial 
Table 2 Indications on the use of hypofractionated radiation therapy for breast cancer in Catalonia, with consensus-based recommendations ( $>80 \%$ agreement among working group members) marked with an asterisk

1. Hypofractionation is indicated in patients who have undergone breast-conserving surgery, regardless of tumour size*

Recommendation: strong

Quality of evidence: high

Justification RCTs have shown hypofractionated treatment to be effec-

Degree of consensus: $95 \%$ tive in tumours of up to $5 \mathrm{~cm}$ in diameter, so it is indicated following breast-conserving treatment in T1-T2 tumours $[1,2]$

2. Hypofractionation is indicated in patients who have undergone breast-conserving surgery, including in women with nuclear grade 3 tumours*

Recommendation: strong

Quality of evidence: high

Degree of consensus: $98 \%$

Justification RCTs have not found any unfavourable effects associated with a high nuclear grade. In one trial, a second pathological review confirmed this issue $[17,18]$. This could be related to the different pathological grading methodology applied by pathologists [19]

3. Hypofractionation is indicated in patients who have undergone breast-conserving surgery, independently of molecular subtype*

Recommendation: strong

Quality of evidence: moderate

Degree of consensus: $97 \%$
Justification In some included RCTs, molecular subtypes were not differentiated, or some were poorly represented, so the quality of the available evidence on the equivalence of hypofractionated treatment is not high. Despite the data showing good local tumour control, this tends to be lower for luminal B and basal molecular subtypes [17]

4. Hypofractionation is indicated in patients who have undergone breast-conserving surgery, independently of the laterality of the breast requiring treatment*

Recommendation: strong

Quality of evidence: high

Degree of consensus: 99\%

Justification Although RCTs have not stratified their results by laterality, indirectly it can be inferred that there are no differences in the fractionation scheme nor greater toxicity per dose in critical organs, or greater toxicity on the left side. Also, non-randomised trials with long follow-up have not found differences according to the side affected by the tumour [1,2]

5. Hypofractionation is indicated in patients who have undergone breast-conserving surgery, independently of whether they receive neoadjuvant chemotherapy*

Recommendation: strong

Quality of evidence: low

Degree of consensus: $89 \%$

Justification Hypofractionation studies included patients receiving adjuvant chemotherapy, with no unfavourable impact. Thus, the consensus of the working group was that this intervention was safe in patients receiving primary systemic treatment with chemotherapy, targeted therapy, or hormone therapy [19]

6. Hypofractionation is indicated in patients who have undergone breast-conserving surgery, independently of whether they receive adjuvant chemotherapy*

Recommendation: strong

Quality of evidence: high

Degree of consensus: 95\%

Justification Although adjuvant chemotherapy was used in only $11 \%$ to $36 \%$ of participants in RCTs, Shaikh's meta-analysis shows the safety of this treatment in hypofractionated patients [8]

7. Hypofractionation is indicated in patients who have undergone breast-conserving surgery and whose age is 40 to 50 years*

Recommendation: strong

Quality of evidence: high

Degree of consensus: $88 \%$

Justification There is enough evidence to support hypofractionated treatment in patients of all ages $[1,2]$

8. Hypofractionation is indicated in patients who have undergone breast-conserving surgery and whose age is less than 40 years

Recommendation: conditional

Quality of evidence: moderate

Degree of consensus: $63 \%$

Justification There is sufficient evidence to support hypofractionated treatment in patients regardless of age, even though the proportion of younger women in trials is lower; moreover, evidence indicates that younger patients show better tolerance to hypofractionated treatment [21]

9. Hypofractionation is indicated in patients who have undergone breast-conserving surgery, including for histology that is exclusively carcinoma in situ

Recommendation: conditional

Quality of evidence: low

Degree of consensus: $72 \%$

Justification Despite the low quality of evidence, the same criteria were applied to hypofractionated radiotherapy for pure carcinoma in situ as to invasive tumours, pending results from an ongoing RCT (RTOG 9804) that specifically assesses this question [20]

10. Hypofractionation is indicated in patients who have undergone breast-conserving surgery, regardless of the size of the breast*

Recommendation: strong

Quality of evidence: high

Degree of consensus: $95 \%$
Justification State-of-the-art technologies allow a greater homogeneity of the dose, so increasing the dose per fraction would imply that the size of the breast is irrelevant [22-24] 
Table 2 (continued)

11. Hypofractionation is indicated in patients who have undergone radical treatment and mastectomy

Recommendation: conditional

Quality of evidence: moderate

Degree of consensus: $64 \%$

Justification Only one RCT has included patients who underwent mastectomy showing that hypofractionation was not inferior in efficacy and had similar toxicities, so the level of evidence cannot be considered high [25], and the degree of consensus was low

12. Hypofractionation is indicated in patients receiving surgery for breast cancer who require nodal irradiation due to the involvement of lymph nodes

Recommendation: conditional

Quality of evidence: low

Degree of consensus: $59 \%$

Justification Given the lack of evidence, further studies are needed to specifically analyse the safety of regional lymph node irradiation using hypofractionated schemes, as evidence only exists for irradiation of the lower axilla, not for an intentional target volume encompassing the axillary region [26]. For this reason, the level of consensus was low

13. Hypofractionation is indicated in patients who have undergone breast-conserving surgery and have an indication for a tumour bed boost*

Recommendation: strong Quality of evidence: high

Degree of consensus: $97 \%$
Justification RCTs included a tumour bed boost following hypofractionated treatment of the breast when indicated confirming the safety of this modality [2]
Recommendation: strong

Quality of evidence: low

Degree of consensus: $94 \%$
Justification The boost can be performed with standard or hypofractionation (14-16 Gy to 2 Gy or $10-12.5$ Gy to $2.5 \mathrm{~Gy}$ ). The level of consensus was high because the use of 2.5 Gy per fraction has already been considered [27]

$R C T$ randomised controlled trial

has also been observed by other authors, for example Gilbo et al. [29], who observed an improvement in utilisation rates from 49 to $80 \%$ in the 4 years following dissemination of the ASTRO guidelines, implementation of clinical practice directives, and follow-up through departmental discussions about clinical indications. As Recht commented in an editorial [30], the use of hypofractionation will only reach recommended levels if specialists are engaged and adherence to guidelines is monitored.

Underpinning this perspective is the assumption that the adoption of healthcare innovations (including process-based innovations like hypofractionation) depends to some extent on how they are communicated and disseminated, not only on the quality of evidence that supports them. To that end, the work described in the present paper followed a consensus-based methodology that incorporates direct knowledge related to clinical practice into the scientific debate. The involvement of 11 clinical departments in an open research and deliberation process converged in a shared vision about the use of hypofractionation, both where a high level of scientific evidence supports its use and where the strength of the evidence is more limited. Following the literature review and the pooling of knowledge among experts with regard to the consensus-based recommendations on the use of hypofractionation in breast cancer, it is significant that 10 of the 14 questions posed yielded full agreement about the intervention. According our results, hypofractionation is appropriate in all patients aged 40 years or more with an indication for adjuvant external beam radiotherapy following breast-conserving surgery for invasive breast carcinoma and without nodal irradiation. The use of hypofractionation schemes in these cases is recommended regardless of other tumour characteristics, like size, histological grade, or molecular subtype; patient characteristics such as size or laterality of the breast; or treatment characteristics, including neoadjuvant or adjuvant chemotherapy, or need for a boost.

The degree of agreement did not meet our $80 \%$ cutoff for consensus in cases where available evidence was insufficient at the time of the review, that is, hypofractionation in patients younger than 40 years, receiving mastectomy, requiring irradiation of the lymph nodes, and with ductal carcinoma in situ. However, over half of the experts supported hypofractionation in all these situations.

Overall, our results are quite similar to the consensus reached by ASTRO [12] and reflected on the guidelines, despite the consideration of the age grouping in our survey and the inclusion of questions about the use of hypofractionation in mastectomized patients or in whom node irradiation is indicated.

Future lines of work, following the application of the consensus-based recommendations, will include an analysis of whether these contribute to changing the use of hypofractionation in breast cancer, standardising practice across the network of Catalan public hospitals. We will also analyse the use of hypofractionation where it is more controversial, for example in cases of immediate reconstruction with prosthesis or autologous graft, concomitant hypofractionated boost 
following intraoperative radiotherapy, or in the presence of autoimmune diseases.

Funding Open Access funding provided thanks to the CRUE-CSIC agreement with Springer Nature.

\section{Declarations}

Conflict of Interest None of the authors declare any conflict of interests.

Ethics approval Not applicable.

Consent to participate Not applicable.

Consent for publication All authors consent to publish the present work.

Avalability of data and material Not applicable.

Code availability Not applicable.

Open Access This article is licensed under a Creative Commons Attribution 4.0 International License, which permits use, sharing, adaptation, distribution and reproduction in any medium or format, as long as you give appropriate credit to the original author(s) and the source, provide a link to the Creative Commons licence, and indicate if changes were made. The images or other third party material in this article are included in the article's Creative Commons licence, unless indicated otherwise in a credit line to the material. If material is not included in the article's Creative Commons licence and your intended use is not permitted by statutory regulation or exceeds the permitted use, you will need to obtain permission directly from the copyright holder. To view a copy of this licence, visit http://creativecommons.org/licenses/by/4.0/.

\section{References}

1. Whelan TJ, Pignol JP, Levine MN, Julian JA, MacKenzie R, Parpia S, et al. Long-term results of hypofractionated radiation therapy for breast cancer. N Engl J Med. 2010;362:513-20. https://doi.org/10.1056/NEJMoa0906260.

2. Yarnold J. Changes in radiotherapy fractionation-breast cancer. Br J Radiol. 2018. https://doi.org/10.1259/bjr.20170849.

3. Haviland JS, Owen JR, Dewar JA, Agrawal RK, Barrett J, BarrettLee PJ, et al. The UK Standardisation of Breast Radiotherapy (START) trials of radiotherapy hypofractionation for treatment of early breast cancer: 10-year follow-up results of two randomised controlled trials. Lancet Oncol. 2013;14:1086-94. https://doi.org/ 10.1016/S1470-2045(13)70386-3.

4. Society A, Oncology R. American Society for Radiation Oncology Ten Things Physicians and Patients Should Question Don't initiate whole breast radiotherapy as a part of breast conservation American Society for Radiation Oncology ten things physicians and patients should question. 2018;2013:23-6. https://www.choos ingwisely.org/wp-content/uploads/2015/02/ASTRO-ChoosingWisely-List.pdf.

5. Montero A, Sanz X, Hernanz R, Cabrera D, Arenas M, Bayo E, et al. Accelerated hypofractionated breast radiotherapy: FAQs
(Frequently Asked Questions) and facts. Breast. 2014;23:299309. https://doi.org/10.1016/j.breast.2014.01.011.

6. Leong N, Truong PT, Tankel K, Kwan W, Weir L, Olivotto IA. Hypofractionated nodal radiation therapy for breast cancer was not associated with increased patient-reported arm or brachial plexopathy symptoms. Int J Radiat Oncol Biol Phys. 2017;99:1166-72. https://doi.org/10.1016/j.ijrobp.2017.07.043.

7. Khan AJ, Poppe MM, Goyal S, Kokeny KE, Kearney T, Kirstein $\mathrm{L}$, et al. Hypofractionated postmastectomy radiation therapy is safe and effective: first results from a prospective phase II trial. J Clin Oncol. 2017. https://doi.org/10.1200/JCO.2016.70.7158.

8. Shaikh F, Chew J, Hochman T, Purswani J, Maisonet O, Peat E, et al. Hypofractionated whole-breast irradiation in women less than 50 years old treated on 4 prospective protocols. Int J Radiat Oncol Biol Phys. 2018;101:1159-67. https://doi.org/10.1016/j. ijrobp.2018.04.034.

9. Chan S, Sutradhar R, Yao Z, Chow E, Lee J, Wan BA, et al. Fractionation in adjuvant radiotherapy for invasive breast cancer and ductal carcinoma in situ in Ontario, Canada from 2009 to 2015. Breast J. 2020;26:602-16. https://doi.org/10.1111/tbj.13515.

10. Ong WL, Millar JL, Foroudi F, Khor R. Are we choosing wisely? - pattern of hypofractionated radiation therapy use for early breast cancer in Victoria, Australia from 2012 to 2017. Int J Radiat Oncol. 2019;105:E30. https://doi.org/10.1016/j.ijrobp. 2019.06.684.

11. Prades J, Algara M, Espinàs JA, Farrús B, Arenas M, Reyes V, et al. Understanding variations in the use of hypofractionated radiotherapy and its specific indications for breast cancer: a mixedmethods study. Radiother Oncol. 2017;123:22-8. https://doi.org/ 10.1016/j.radonc.2017.01.014.

12. Smith BD, Bellon JR, Blitzblau R, Freedman G, Haffty B, hahn $\mathrm{C}$, et al. Radiation therapy for the whole breast: Executive summary of an American Society for Radiation Oncology (ASTRO) evidence-based guideline. Pract Radiat Oncol. 2018;8:145-52. https://doi.org/10.1016/j.prro.2018.01.012.

13. Andrews J, Guyatt G, Oxman AD, Alderson P, Dahm P, FalckYtter Y, et al. GRADE guidelines: 14. Going from evidence to recommendations: the significance and presentation of recommendations. J Clin Epidemiol. 2013;66:719-25. https://doi.org/ 10.1016/j.jclinepi.2012.03.013.

14. Balshem H, Helfand M, Schünemann HJ, Oxman AD, Kunz R, Brozek J, et al. GRADE guidelines: 3 . Rating the quality of evidence. J Clin Epidemiol. 2011;64:401-6. https://doi.org/10. 1016/j.jclinepi.2010.07.015.

15. Morgan SC, Hoffman K, Loblaw DA, Buyyounouski MK, Patton C, Barocas D, et al. Hypofractionated radiation therapy for localized prostate cancer: executive summary of an ASTRO, ASCO, and AUA evidence-based guideline. Pract Radiat Oncol. 2018;8:354-60. https://doi.org/10.1016/j.prro.2018.08.002.

16. Loblaw DA, Prestrud AA, Somerfield MR, Oliver TK, Brouwers MC, Nam RK, et al. American Society of Clinical Oncology clinical practice guidelines: formal systematic review-based consensus methodology. J Clin Oncol. 2012;30:3136-40. https://doi.org/10. 1200/JCO.2012.42.0489.

17. Bane AL, Whelan TJ, Pond GR, Parpia S, Gohla G, Fyles AW, et al. Tumor factors predictive of response to hypofractionated radiotherapy in a randomized trial following breast conserving therapy. Ann Oncol. 2014;25:992-8. https://doi.org/10.1093/ annonc/mdu090.

18. Rakha EA, Reis-Filho JS, Baehner F, Dabbs DJ, Decker T, Eusebi $\mathrm{V}$, et al. Breast cancer prognostic classification in the molecular era: the role of histological grade. Breast Cancer Res. 2010;12(12):207. https://doi.org/10.1186/bcr2607.

19. Diwanji TP, Molitoris JK, Chhabra AM, Snider JW, Bentzen SM, Tkaczuk KH, et al. Utilization of hypofractionated wholebreast radiation therapy in patients receiving chemotherapy: a 
National Cancer Database analysis. Breast Cancer Res Treat. 2017;165:445-53. https://doi.org/10.1007/s10549-017-4345-y.

20. McCormick B, Winter K, Hudis C, Kuerer HM, Rakovitch E, Smith BL, et al. RTOG 9804: a prospective randomized trial for good-risk ductal carcinoma in situ comparing radiotherapy with observation. J Clin Oncol. 2015;33:709-15. https://doi.org/10. 1200/JCO.2014.57.9029.

21. Meattini I, Lambertini M, Desideri I, De Caluwé A, Kaidar-Person O, Livi L. Radiation therapy for young women with early breast cancer: current state of the art. Crit Rev Oncol Hematol. 2019;137:143-53. https://doi.org/10.1016/j.critrevonc.2019.02. 014.

22. Hannan R, Thompson RF, Chen Y, Bernstein K, Kabarriti $\mathrm{R}$, Skinner $\mathrm{W}$, et al. Hypofractionated whole-breast radiation therapy: does breast size matter? Int J Radiat Oncol Biol Phys. 2012;84:894-901. https://doi.org/10.1016/j.ijrobp.2012.01.093.

23. Patel AK, Ling DC, Richman AH, Champ CE, Huq MS, Heron $\mathrm{DE}$, et al. Hypofractionated whole-breast irradiation in largebreasted women - is there a dosimetric predictor for acute skin toxicities? Int J Radiat Oncol Biol Phys. 2019;103:71-7. https:// doi.org/10.1016/j.ijrobp.2018.08.024.

24. Ratosa I, Jenko A, Oblak I. Breast size impact on adjuvant radiotherapy adverse effects and dose parameters in treatment planning. Radiol Oncol. 2018;52:233-44. https://doi.org/10.2478/ raon-2018-0026.

25. Wang SL, Fang H, Song YW, Wang WH, Hu C, Liu YP, et al. Hypofractionated versus conventional fractionated postmastectomy radiotherapy for patients with high-risk breast cancer: a randomised, non-inferiority, open-label, phase 3 trial. Lancet
Oncol. 2019;20:352-60. https://doi.org/10.1016/S1470-2045(18) 30813-1.

26. Bellefqih S, Elmajjaoui S, Aarab J, Khalil J, Afif M, Lachgar A, et al. Hypofractionated regional nodal irradiation for women with node-positive breast cancer. Int J Radiat Oncol Biol Phys. 2017;97:563-70. https://doi.org/10.1016/j.ijrobp.2016.11.010.

27. Palumbo I, Mariucci C, Falcinelli L, Perrucci E, Lancellotta V, Podlesko AM, et al. Hypofractionated whole breast radiotherapy with or without hypofractionated boost in early stage breast cancer patients: a mono-institutional analysis of skin and subcutaneous toxicity. Breast Cancer. 2019;26:290-304. https://doi.org/10.1007/ s12282-018-0923-z.

28. Andermann A, Pang T, Newton JN, Davis A, Panisset U. Evidence for Health II: overcoming barriers to using evidence in policy and practice. Health Res Policy Syst. 2016;14:17. https://doi.org/10. 1186/s12961-016-0086-3.

29. Gilbo P, Potters L, Lee L. Implementation and utilization of hypofractionation for breast cancer. Adv Radiat Oncol. 2018;3:265-70. https://doi.org/10.1016/j.adro.2018.04.001.

30. Recht A. Breast cancer fractionation patterns: why aren't they uniform, and should they be? Breast J. 2020;26:599-601. https:// doi.org/10.1111/tbj.13578.

Publisher's Note Springer Nature remains neutral with regard to jurisdictional claims in published maps and institutional affiliations.

\section{Authors and Affiliations}

\section{Arantxa Eraso ${ }^{1} \cdot$ Javier Sanz ${ }^{2}$ (1) $\cdot$ Meritxell Mollà $^{3} \cdot$ Vicky Reyes $^{4} \cdot$ Agustí Pedro $^{5} \cdot$ Meritxell Arenas $^{6}$. Evelyn Martinez ${ }^{7} \cdot$ Rosa Ballester $^{8} \cdot$ Maria José Cambra $^{9}$. Virginia García ${ }^{10}$. Joan Lluis Prades ${ }^{11}$. Josep M. Borras ${ }^{11}$. Manuel Algara ${ }^{2}$}

1 Radiation Oncology Department, Institut Català d'Oncologia Girona, Avda de França,0, 17007 Girona, Spain

2 Radiation Oncology Department, Hospital del Mar, Edifici B, -2. C/ del Gas s/n, 08003 Barcelona, Spain

3 Radiation Oncology Department, Hospital Clínic de Barcelona, C/ Villarroel 170, 08036 Barcelona, Spain

4 Radiation Oncology Department, Hospital Universitari Vall d'Hebron, Pass. de la Vall d'Hebron 119, 08035 Barcelona, Spain

5 Radiation Oncology Department, Hospital de la Santa Creu i Sant Pau, C/ Sant Antoni Maria Claret 167, 08025 Barcelona, Spain

6 Radiation Oncology Department, Hospital Universitari Sant Joan de Reus, Avda Doctor Josep Laporte 2, 43204 Reus, Spain
7 Radiation Oncology Department, Institut Català d'Oncologia, Hospital Duran i Reynals, Avda Gran Via de l'Hospitalet, 199-203, 08908 L'Hospitalet de Llobregat, Spain

8 Radiation Oncology Department, Institut Català d'Oncologia Badalona, Carretera del Canyet s/n, 08916 Badalona, Spain

9 Radiation Oncology Deparment, Hospital General de Catalunya, C/ Pere i Pons 1, 08190 Sant Cugat del Vallés, Spain

10 Radiation Oncology Departement, Hospital Universitari Arnau de Vilanova, Av. Alcalde Rovira Roure, 80, 25198 Lleida, Spain

11 Pla Director d'Oncologia de Catalunya, Institut Català d'Oncologia, Hospital Duran i Reynals, Avda Gran Via de l'Hospitalet, 199-203, 08908 L'Hospitalet de Llobregat, Spain 